\title{
Two new species of the family Syringophilidae (Acari: Cheyletoidea) from passeriform birds collected in the Altai
}

\author{
Andre Bochkov $^{1}$ and Dmitry Apanaskevich ${ }^{2}$ \\ ${ }^{1}$ Institut royal des Sciences naturelles de Belgique, rue Vautier 29, B-1000 Bruxelles, Belgique; \\ ${ }^{2}$ Zoological Institute, Russian Academy of Sciences, Universitetskaya Emb. 1, 199034 Saint-Petersburg, Russia
}

Key words: Acari, Syringophilidae, Passeriformes, parasites, new species, Altai

\begin{abstract}
Two new species of the syringophilid mites (Acari: Syringophilidae) are described from quills of passeriform birds. Syringophilopsis faini sp. $\mathrm{n}$. is described from Sylvia curruca (L.) (Sylviidae) and Syringophiloidus carpodaci sp. n. is described from Carpodacus erythrinus (Pall.) (Fringillidae). Characters are detailed that differentiate Syringophilopsis faini from three species of a new "turdus" group, and Syringophiloidus carpodaci from S. minor.
\end{abstract}

The mites of the family Syringophilidae Lavoipierre, 1953 (Acari: Cheyletoidea) are permanent monoxenous or oligoxenous parasites inhabiting the quills of feathers of birds, and are known from 13 avian orders (Kethley and Johnston 1975). The syringophilid mites of the world, as well as of the former USSR, are poorly known. The family contains about 65 species assigned to 24 genera (Kethley 1970, Bochkov and Mironov 1998, Skoracki 1999). However, it has been suggested that the world fauna of the Syringophilidae might include at least 5000 species (Johnston and Kethley 1973). In the present paper, we give descriptions of two new species of syringophilids collected from Sylvia curruca (L.) (Sylviidae) and Carpodacus erythrinus (Pall.) (Fringillidae).

\section{MATERIALS AND METHODS}

Birds, collected in the South-western Altai by the junior author, were preserved in alcohol and later, quills were examined for mites under a dissection microscope. Mites were removed with a sharp pincette and mounted in Fora-Berlese medium on glass microscope slides.

The terminology for morphology and leg chaetotaxy follows that of Kethley (1970). The nomenclature of Fain (1979) is used for idiosomal chaetotaxy. His system was originally developed for the Cheyletidae, but it was recently shown to be applicable to all families of the Cheyletoidea (Bochkov and Mironov 1998, Bochkov et al. 1999). All measurements are given in micrometres with ranges in parentheses.

\section{RESULTS}

Family S y r ing o p h i lid a e Lavoipierre, 1953

\section{Syringophilopsis faini sp. n.}

Figs. 1, 2

Female (holotype). Body length, including gnathosoma, 855 (910-980 in 4 paratypes), width at level of bases of setae $h 190$ (170-190). Hypostomal apex with one pair of finger-like median protuberances. Cheliceral digit with 3 teeth. Peritremes arch-like, with 16 (15-17) chambers. Dorsum: Propodosomal plate weakly sclerotised with indistinct margins. Hysterosomal plate present, very poorly sclerotised. Length of setae: vi 45 (47-67), ve 51 (54-74), sci 69 (78-90), sce 247 (234-247), h 230 (211235), d1 238 (247-270), d2 171 (184-200), d4 47 (42-49), d5 38 (31-39), l1 265 (220-260), $l 2180$ (180-205), $l 4195$ (180-166), $l 5290$ (250-290). Distance between $l 1$ and $d 2$ 67 (67-83), $d 2$ and $l 256$ (60-67). Venter: Cuticular striations as in Fig. 1B. Length of setae: icl 110 (85-95), ic3 60 (47-55), pg1 132 (100-140), pg2 145 (135-153), pg3 180 (157-200), $g 1$ and $g 2$ approximately 45 (40-45), $a 1$ and $a 2$ approximately 30 (24-29). Legs: Coxae I-IV weakly sclerotised and ornamented. Setae scIII, scxIV approximately 33 (30-33). Setae $a^{\prime}$, $a$ "' of tarsi I-II with 67 tines, $a$ ', $a$ " of tarsi III-IV with 9-11 tines. Setae $t c$ 'III-IV and $t c " I I I-I V$ subequal.

Male. Body length, including gnathosoma, 596-675 in 3 paratypes, width at level of bases of $h$ 200-225. Lateral branch of peritremes with 3 chambers, longitudinal branch with 12-14 chambers. Hysterosomal plate striated, with indistinct margins. Length of setae: vi 18-27, ve 24-29, sci 32-40, sce 96-105, $h$ 56-83, d 1 90-112, d2 13-16, d5 1822, ll 30-47, l2 13-16, l5 60-90, pg1 45-58, pg2 30-33, pg3 40-58.

T y p e h o s t: Sylvia curruca (L.), the lesser whitethroat (Passeriformes: Sylviidae).

Site of infestation: Quills.

T y p e 1 o c a 1 i t y : South-western Altai (Kazakhstan), Zyryanovskii Distr., near the village of Shumovsk.

D a t e of c olle cti o n: May, 2000, D. Apanaskevich coll.

$\mathrm{T}$ y p e m a t e r i a 1: Holotype female, 4 female and 2 male paratypes.

De p o s ition of mat e ri a 1 : Holotype female (Coll. No. T-Sy-16), 3 female paratypes (Coll. No. P-Sy-16, N 1-3), 1 paratype male (Coll. No. P-Sy-16, N 4) in the Zoological 


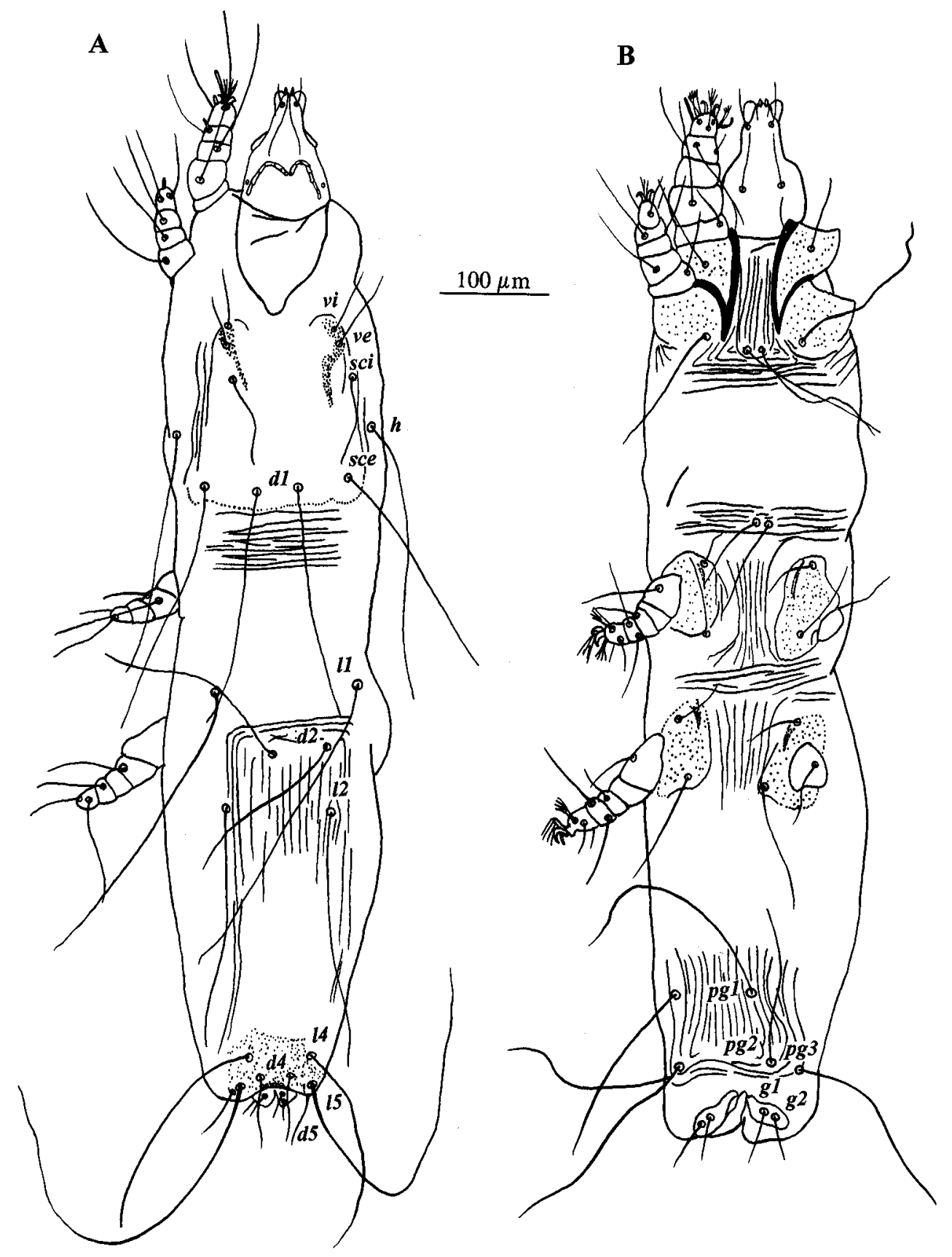

Fig. 1. Syringophilopsis faini sp. n., female holotype. A - dorsal view; B - ventral view.

Institute of the Russian Academy of Sciences, SaintPetersburg; 1 paratype female and 1 paratype male (Coll. No. PAU AVČR 1984) in the Institute of Parasitology, Academy of Sciences of the Czech Republic, České Budějovice.

E t y m o lo g y: The species is named in honour of the famous acarologist, Prof. Dr. Alex Fain (Belgium).

Differential diagnosis. The new species belongs to the new species group "turdus" containing three other species: Syringophilopsis turdus (Fritsch, 1958) from Turdus pilaris (Passeriformes: Turdidae) from Germany (Fritsch 1958), S. acrocephali Skoracki, 1999 from Acrocephalus scirpaceus (Passeriformes: Sylviidae) from Poland (Skoracki 1999) and S. sturni Chirov et Kravtsova, 1995 from Sturnus vulgaris (Passeriformes: Sturnidae) from Kirghizia and Kazakhstan (Chirov and Kravtsova 1995, Bochkov and Mironov 1998). In this species group, $d 4$ and $d 5$ of females are relatively short, one-third to one-sixth the length of $l 4,15$, respectively. Females of $S$. faini are easily distinguished from all species of the "turdus" group by sci being about $69-90$ and the ratio of $v i$ : ve being $1: 1$. In the other species, $s c i$ are long (over 200), and $v i$ are one-half to one-fifth the length of ve. The new species is most 

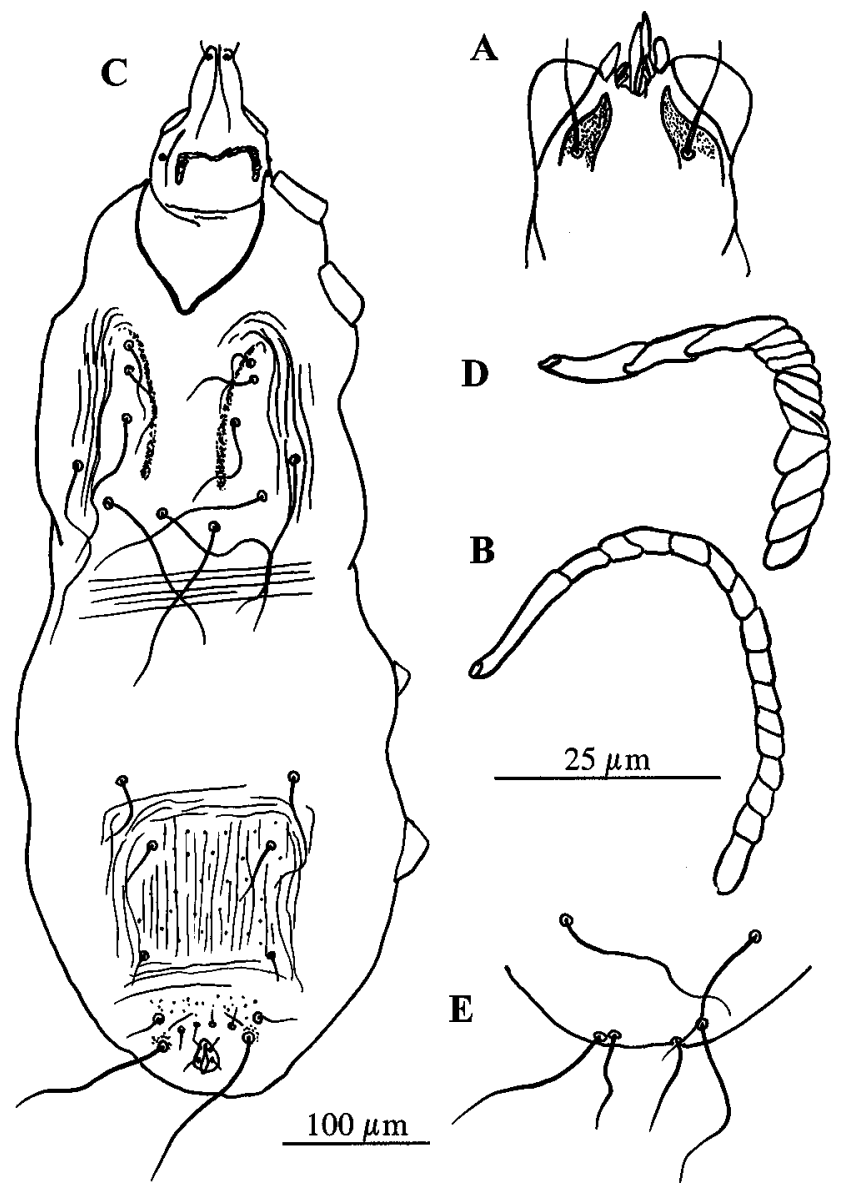

Fig. 2. Syringophilopsis faini sp. n. A - hypostomal apex of female, holotype, ventral view; $\mathbf{B}$ - peritreme of female, holotype; $\mathbf{C}$ - male, dorsal view; $\mathbf{D}$ - peritreme of male; $\mathbf{E}$ opisthosoma of male, ventral view. Scale bars: A, B, D $=25 \mu \mathrm{m}$; $\mathrm{C}, \mathrm{E}=100 \mu \mathrm{m}$.

closely related to $S$. sturni, but may be distinguished easily. In $S$. faini, vi, $d 4, d 5$ and $g$ are short, 47, 29, 33 and 27 , respectively, the median protuberances of the hypostomal apex are finger-like, and the hysterosomal plate is present. In $S$. sturni, vi, $d 4, d 5$ and $g$ are relatively long, $87,81,61$ and 87 , respectively, the median protuberances of the hypostomal apex are short, there is no hysterosomal plate, and there are only small sclerotised plates around setae.

\section{Syringophiloidus carpodaci $\mathrm{sp} . \mathrm{n}$.}

Fig. 3

Female (holotype). Body length, including gnathosoma, 670 (660-710 in 10 paratypes), width at level of bases of $h 140$ (110-150). Hypostomal apex without median protuberances. Lateral branch of peritreme with 5 (5-7) chambers, longitudinal branch with 9 (9-10) chambers. Propodosomal plate well developed, with distinct lateral margins. Hysterosomal plate absent.
Dorsum: $v i$, ve and $s c i$ weakly serrate. Length of setae: $v i$ 36 (33-40), ve 56 (50-67), sci 112 (80-135), sce 160 (150200), h 145 (130-180), d1 180 (175-220), d2 150 (135160), d4 27 (27-31), d5 31 (29-33), l1 165 (160-190), l2 145 (140-155), $l 4165$ (160-180), 15300 (250-340). Setae $d 2$ about half the distance from $l 1$ than from $l 2$. Venter: Length of setae: pgl 115 (115-135),pg2 110 (110-140), pg3 155 (155-180), $g 1$ and $g 230$ (25-34), al and $a 218$ (15-20). Legs: Coxae I-IV weakly sclerotised, without ornamentation. Setae scIII and scxIV extending beyond respective genua. Setae $t c$ ' $I I I-I V$ twice the length of $t c$ " $I I$ IV.

Male. Body length, including gnathosoma, 450-480 in 10 paratypes, width at level of bases of $h$ 140-170. Lateral branch of peritreme with 7-9 chambers, longitudinal branch with 6-7 chambers. Length of setae: vi 24-31, ve 30-47, sci 31-56, sce 90-105, $h$ 100-125, d1 105-120, d2 12-16, d5 15-20, l1 40-56, l2 12-16, l5 145-180, pgl 4972, pg2 56-67.

$\mathrm{T}$ y p e h o s t: Carpodacus erythrinus (Pall.), the common rosefinch (Passeriformes: Fringillidae).

Site of infestation: Quills.

T y p e 1 o c a 1 i t y : South-western Altai (Kazakhstan), Zyryanovskii Distr., near the village of Shumovsk.

D a te of c o 11 e cti on: May, 2000, D. Apanaskevich coll.

$\mathrm{T}$ y pe m at e r i a 1 : Holotype female, 15 female and 15 male paratypes.

A d d ition a 1 mate rial: 15 females and 15 males from the same host species with the same collection data.

De p o s ition of mate ria 1 : Holotype female (Coll. No. T-Sy-17), 14 female paratypes (Coll. No. P-Sy-17, N 1-14), 14 male paratypes (Coll. No. P-Sy-17, N 15-28) and all additional material in the Zoological Institute of the Russian Academy of Sciences, Saint-Petersburg; 1 paratype female and 1 paratype male (Coll. No. PAU AVČR 1985) in the Institute of Parasitology, Academy of Sciences of the Czech Republic, České Budějovice.

E t y m o 1 o g y : The name carpodaci refers to the generic name of the host.

Differential diagnosis. The new species is similar to Syringophiloidus minor (Berlese, 1887), known from Passer domesticus (Passeriformes: Ploceidae) from Europe and North America (Fritsch 1958, Kethley 1970) and $P$. montanus from Russia (Bochkov and Mironov 1998). In females of both species, the lateral branch of peritreme consists of numerous short chambers and $v i$ and $v e$ are slightly serrate. These species can be distinguished by a number of characters. In $S$. carpodaci, the length of $v i$, ve and sci in females is 33-40, 50-67 and 80-135, respectively; the length of $l 1$ in males is 40-56. In $S$. minor (20 females and 10 males from $P$. domesticus from Kirghizia and 10 females and 5 males from the same host from the town of Samara, Russia), the length of $v i$, ve and sci in females is 22-33, 33-42 and 30-70, respectively; the length of $l 1$ in males is 22-30. 


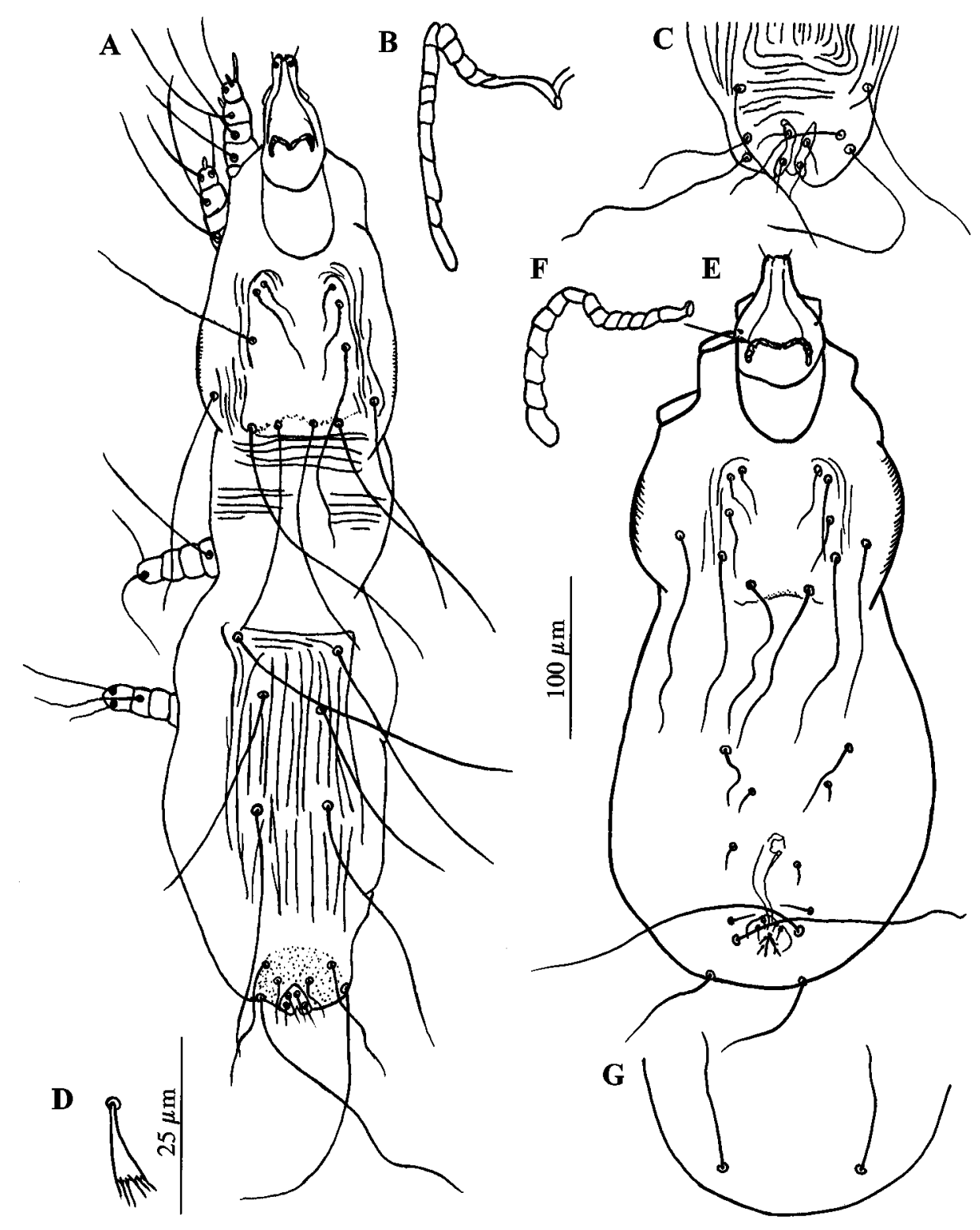

Fig. 3. Syringophiloidus carpodaci sp. n. A - female, holotype, dorsal view; $\mathbf{B}$ - peritreme of female, holotype; $\mathbf{C}$ - opisthosoma of female, holotype, ventral view; D - seta a"IV of female, holotype; $\mathbf{E}$ - male, dorsal view; F - peritreme of male; $\mathbf{G}$ - opisthosoma of male, ventral view. Scale bars: A, C, E, G $=100 \mu \mathrm{m}$; B, D, F $=25 \mu \mathrm{m}$.

Remarks. Two females of S. minor and the holotype of $S$. carpodaci were collected from the same host specimen. Furthermore, two females of S. minor were collected from C. erythrinus from Novgorod Province, Russia in July, 1999, the first time that $S$. minor has been collected from this host.
Acknowledgements. We thank Dr. S. Mironov (Zoological Institute of the Russian Academy of Sciences, Russia) and Prof. T. Galloway (University of Manitoba, Canada) for critically reviewing the manuscript. The research was supported by grant No. 00-04-48885 from the Russian Foundation for Basic Research and Belgian Federal Services for Scientific, Technical and Cultural Affairs. 


\section{REFERENCES}

BOCHKOV A.V., MIRONOV S.V. 1998: Quill mites of the family Syringophilidae Lavoipierre, 1953 (Acariformes: Prostigmata) parasitic on birds (Aves) of the fauna of the former USSR. Acarina 6: 3-16.

BOCHKOV A.V., MIRONOV S.V., FAIN A. 1999: Phylogeny and host-parasite relationships of the mite family Harpirhynchidae (Acari: Cheyletoidea). Acarina 7: 69-87.

CHIROV P.A., KRAVTSOVA N.T. 1995: A new genus and new species of mites of the family Syringophilidae. Parazitologiya 29: 370-379. (In Russian.)

FAIN A. 1979: Idiosomal and leg chaetotaxy in the Cheyletidae. Int. J. Acarol. 5: 305-310.

FRITSCH W. 1958: Die Milbengattung Syringophilus Heller, 1880 (Subordo Trombidiformes, Fam. Myobiidae Mégnin, 1877). Zool. Jahrb. Syst. 86: 227-234.

Received 7 August 2000
JOHNSTON D.E., KETHLEY J.B. 1973: A numerical phenetic study of the quill mites of the family Syringophilidae (Acari). J. Parasitol. 59: 520-530.

KETHLEY J.B. 1970: A revision of the family Syringophilidae (Prostigmata, Acarina). Contrib. Am. Entomol. Inst. 5: 1-76.

KETHLEY J.B., JOHNSTON D.E. 1975: Resource tracking in bird and mammalian ectoparasites. Misc. Publ. Entomol. Soc. Am. 9: 229-236.

SKORACKI M. 1999: New genus and species of Syringophilidae from Eurasian Reed-Warbler, Acrocephalus scirpaceus (Sylviidae: Passeriformes) (Acari: Prostigmata). Genus 10: 155-162.

Accepted 15 March 2001 